\title{
Development of preeclampsia in a pregnant patient with FMF
}

Volume 3 Issue 4 - 2015

\section{Letter to Editor}

Familial mediterrean fever (FMF) is an autosomal recessive disease characterized by recurrent self limiting attacks of fever, serositis (like peritonitis, arthritis, pleuritis) and eryzipelas-like skin lesion. The disease is common among Turks, Armenians, Arabs and non askanazy Jews and the prevalence of FMF in the Turkish population is estimated to be 1:400 to 1:1000. And the majority of patients develop FMF before 20 years of age ${ }^{1}$ and most patients of FMF have their first attack at the early childhood. ${ }^{2}$ FMF may cause amyloidosis that is a generic term that refers to the extracellular tissue deposition of beta-sheet fibrils, many of which circulate as constituents of plasma and it affects the kidneys but may also be accumulated in other organs such as the heart, gastrointestinal tract, and reproductive organs. ${ }^{3}$ Preeclampsia is characterised by hypertension and proteinuria developing in a pregnant woman after 20 weeks' gestation and it is a major cause of maternal and perinatal mortality and morbidity. ${ }^{4}$ Preeclampsia is also recognised as a significant risk factor for maternal cardiovascular morbidity later in life such as chronic hypertension, ischaemic heart disease, stroke and venous thromboembolism. ${ }^{6}$ The aim of this letter to the editor is to share our experience development of preeclampsia in a pregnant patient with fmf. 30 years old female patient with a diagnosis of FMF is followed for 10 years and using colchicine treatment was continued at the dose of $2 * 1$ regularly and no nefropathy and amyloidosis history. Patient's had an unknown cause infertility and became pregnant after the fourth in vitro fertilization. At 24 week for pregnancy she was evaluated at nephrology outpatient clinic. No proteinurea or amyloidosis findings were found and arterial blood pressure values were normal. Moreover, she had no further FMF episodes during pregnancy. The patient's blood pressure was increased at the 36th week of pregnancy. Her blood pressure was around $170 / 100 \mathrm{~mm}$. Following urgent intervention with $(1500 \mathrm{mg})$ alpha methyl dopa and (120mg) nifedipin, proteinurea amount was $>300 \mathrm{mg} /$ day and uric acid level was around $8 \mathrm{mg} / \mathrm{dl}$. Creatine value was $0,5 \mathrm{mg} / \mathrm{dl}$ and albumin level $2.5 \mathrm{gr} / \mathrm{dl}$ preeclampsia was considered. The patient was considered as preeclampsia. The patient was evaluated by obstretrics and nephrology departments and emergency termination of pregnancy was planned. After cesarean section, her clinical picture improved rapidly. Blood pressure values could be regulated with low dose $(30 \mathrm{mg})$ nifedipin. Proteinurea dropped below $<300 \mathrm{mg} /$ day and the patient was discharged in stable condition. At nephrology control ten days later, nifedipin was discontinued. She is still on colchicine treatment and following pregnancy, she had no FMF attacks. She has no proteinurea, nephropathy and amilyoidosis and blood pressure values are within normal ranges. In the literature search we found only few cases with FMF during pregnancy and complicated with preeclampsia. ${ }^{3}$ The course of disease in female FMF patients during pregnancy is variable. Some patients have an attack free period during pregnancy and still other women may experience attacks with high frequency. FMF may cause adverse outcomes to a pregnancy and may also increase the perinatal and maternal

\author{
Oznur Kal,' Emel Ozcimen² \\ 'Baskent University Medical Faculty Department of Nephrology, \\ Turkey \\ ${ }^{2}$ Baskent University Medical Faculty Department of Gynecology, \\ Turkey
}

Correspondence: Oznur Kal, Baskent University Medical Faculty Konya Hospital, Department Of Nephrology, Konya, Turkey,Tel+905065 I67270, Email dr.oznurkal@yahoo.com

Received: November 10, 2015 | Published: November 13, 2015

complications by chronic effects and acute attacks. ${ }^{3}$ Apart from the inconcience and the pain during the attacks there is an additional risk, because peritonitis may lead to uterine contractions with eventual abortions, early labor and delivery. During the pregnancy the onset of hypertension and proteinuria after 20 weeks gestation characterizes preeclampsia, a leading cause of maternal mortality. Preeclampsia has been recognized as a potentially fatal complication of pregnancy for more than a century. It complicates between $\% 3$ and $\% 10$ of pregnancies and is responsible for a large partion of maternal and perinatal morbidity and death. Livneh A et al. ${ }^{6}$ reported that the level of creatinine and proteinuria at the time of conception is the cornerstone for predicting complications for patients with FMF complicated with amyloidosis. Amyloidosis based on the initial renal function may adversely affect pregnancies and additional comorbid diseases especially chronic hypertension may aggressively deteriorate the situation of the patients. ${ }^{6}$ Yasar et al. ${ }^{7}$ implicated that renal involvement in FMF patients manifested as proteinuria might lead to increased pregnancy complications even in early phases. Colchicine is very important for FMF control and it prevents the renal disease and may delay the occurring of amyloidosis. Colchicine crosses transplacentally but its safety for fetus and placenta has been reported before. ${ }^{6,8}$ Colchicine treatment is safe in pregnancy and may lead to a decreased miscarriage rate. FMF may trigger preeclampsia during pregnancy and FMF is independently influencing complications than general population, but colchicine has great effects on the perinatal and maternal outcomes of patients with FMF. Pregnant FMF patients without nephropathy and amyloidosis, should be followed closely for preeclampsia.

\section{Conflicts of Interest}

The authors do not have any Conflict of interests.

\section{Acknowledgments}

None. 


\section{Funding}

None.

\section{References}

1. Ben-Chetrit E, Levy M. Familial Mediterranean fever. Lancet. 1998;351(9103): 659-664.

2. Sohar E, Gafni J, Pras M, et al. Familial Mediterranean fever. A survey of 470 cases and review of the literature. Am J Med. 1967;43(2):227-253.

3. Turgal M, Selcuk I, Ozyuncu O. Pregnancy of five outcome patients with renal amyloidosis regarding familkial Mediterrenean fever. Ren Fail. 2014;36(2): 306-308.

4. Bulletins. ACOG Committee on Practice. ACOG practice bulletin Diagnosis and management of preeclampsia and eclampsia. Obstet Gynecol. 2002;99(1):159-167.
5. Bellamy L, Casas J-P, Hingorani AD, et al. Pre-eclampsia and risk of cardiovascular disease and cancer in later life: systematic review and meta-analysis. BMJ. 2007;335(7672):974.

6. Livneh A, Cabili S, Zemer D, et al. Effect of pregnancy on renal function in amyloidosis of familial Mediterranean fever.J Rheumatol. 1993;20(9):1519-1523.

7. Yasar O, Iskender $\mathrm{C}$, Kaymak $\mathrm{O}$, et al. Retrospective evaluation of pregnancy outcomes in women with familial Mediterrane anfever. $J$ Matern Fetal Neonatal Med. 2014;27(7):733-736.

8. Zemer D, Pras M, Sohar E, et al. olchicine in the prevention and treatment of the amyloidosis of familial Mediterranean fever. $N$ Engl $J$ Med. 1986;314(16):1001-1005. 